\begin{tabular}{|c|c|}
\hline $\begin{array}{l}\text { Chemistry of } \\
\text { Metals and Al }\end{array}$ & $\begin{array}{l}\text { Chem. Met. Alloys } 2 \text { (2009) 10-14 } \\
\text { Ivan Franko National University of LLvv } \\
\text { www. chemetali-journal.org }\end{array}$ \\
\hline
\end{tabular}

\title{
Crystal structure of the $\mathrm{Tl}_{4} \mathrm{GeSe}_{4}$ ternary compound
}

\author{
O.S. GLUKH ${ }^{1}$, M.Yu. SABOV ${ }^{1}$, I.E. BARCHIJ ${ }^{1}$, V.V. PAVLYUK ${ }^{2,3 *}$, B. MARCINIAK ${ }^{3}$ \\ ${ }^{1}$ Uzhgorod National University, Department of Inorganic Chemistry, \\ Pidgirna St. 46, 88000 Uzhgorod, Ukraine \\ ${ }^{2}$ Ivan Franko National University of Lviv, Department of Inorganic Chemistry, \\ Kyryla i Mefodia St. 6, 79005 Lviv, Ukraine \\ ${ }^{3}$ Czestochowa Jan Dtugosz University, Institute of Chemistry and Environmental Protection, \\ Al. Armii Krajowej 13/15, 42200 Czestochowa, Poland \\ * Corresponding author. E-mail: pavlyuk@franko.lviv.ua
}

Received December 3, 2008; accepted June 25, 2009; available on-line November 16, 2009

The crystal structure of the $\mathrm{Tl}_{4} \mathrm{GeSe}_{4}$ compound was determined by $\mathrm{X}$-ray single crystal diffraction. The title compound crystallizes with the $\mathrm{Tl}_{4} \mathrm{SiSe}_{4}$ structure type (space group $\mathrm{C2}_{2} / \mathrm{c}$ ). The $\mathrm{Tl}^{+}$cations are coordinated by four separate $\left[\mathrm{GeSe}_{4}\right]^{4-}$ anions, whereas the $\left[\mathrm{GeSe}_{4}\right]^{4-}$ anion is surrounded by nine $\mathrm{Tl}^{+}$cations. Strengthening of the cation-anion interactions was observed with respect to the Si-compound.

Intermetallics / Crystal structure / X-ray diffraction / Thallium / Germanium / Selenium

\section{Introduction}

Ternary compounds $\mathrm{Tl}_{4} \mathrm{XY}_{4}$ are known in the $\mathrm{Tl}-\mathrm{X}-\mathrm{Y}$ systems where $X=\mathrm{Si}, \mathrm{Ge}, \mathrm{Sn}$ and $\mathrm{Y}=\mathrm{S}$, Se [1-9]. The crystal structures have been investigated for all of these compounds, except for $\mathrm{Tl}_{4} \mathrm{GeSe}_{4}$. The structures are monoclinic and contain isolated $\left[\mathrm{XY}_{4}\right]^{4-}$ tetrahedra. $\mathrm{Tl}_{4} \mathrm{SiS}_{4}$ crystallizes in space group $C c$, with $a=12.518(3), b=11.241(2), c=7.567(2) \AA$, and $\beta=112.80(2)^{\circ}, Z=4$. The compound is isostructural with $\mathrm{Tl}_{4} \mathrm{GeS}_{4}$ and contains $\left[\mathrm{SiS}_{4}\right]^{4-}$ anions held together by $\mathrm{Tl}^{+}$cations in irregular 6-fold coordination. $\mathrm{Tl}_{4} \mathrm{SiSe}_{4}$ crystallizes in space group $C 2 / c, \quad$ with $a=11.664(9), \quad b=7.277(4), \quad c=$ 24.903(12) $\AA$, and $\beta=99.93(5)^{\circ}, Z=8$ [6]. According to Kulieva and Babanly $[3,5], \mathrm{Tl}_{4} \mathrm{GeSe}_{4}$ exists and melts congruently at $661 \mathrm{~K}$.

\section{Experimental details}

\subsection{Synthesis}

$\mathrm{Tl}_{4} \mathrm{GeSe}_{4}$ was synthesised from binary phases $\left(\mathrm{Tl}_{2} \mathrm{Se}\right.$ and $\mathrm{GeSe}_{2}$ ) in evacuated quartz ampoules at $1043 \mathrm{~K}$, and annealed at $703 \mathrm{~K}$ for 96 hours. Thallium(I) selenide and germanium diselenide were prepared from appropriate amounts of high-purity (T1 99.997 wt.\%, Ge 99.9998 wt.\%, Se 99.9998 wt.\%) elemental solids by encapsulating them under vacuum in quartz ampoules and melting in a flame. $\mathrm{Tl}_{2} \mathrm{Se}$ obtained this way was annealed at 703 for 24 hours. $\mathrm{GeSe}_{2}$ was annealed for 24 hours at $1043 \mathrm{~K}$, then the ampoule was turned and again annealed. This procedure was repeated 3-4 times. A $\mathrm{Tl}_{4} \mathrm{GeSe}_{4}$ single crystal was obtained using the Bridgman technique.

\subsection{X-ray diffraction}

Single-crystal X-ray diffraction data for $\mathrm{Tl}_{4} \mathrm{GeSe}_{4}$ were collected at room temperature on a four-circle diffractometer Xcalibur Oxford Diffraction equipped with a CCD detector (graphite monochromatized Mo $K \alpha$ radiation). Scans were taken in the $\omega$ mode. The crystal structure was successfully solved by direct methods and refined using programs from the SHELX-97 package $[10,11]$.

\subsection{Chemical analysis}

The weighted (0.1-0.5 g) crystal was dissolved in a $50 \mathrm{ml}$ mixture of concentrated $\mathrm{HCl}$ and $30 \% \mathrm{H}_{2} \mathrm{O}_{2}$. Germanium was extracted by $\mathrm{CCl}_{4}$ and then reextracted by water from the extract. A drop of phenolphthalein was added and then $\mathrm{NaOH}$ was added until the solution became pink. The alkali was neutralized by $2-3$ drops of $1 \mathrm{~N} \mathrm{HCl}$, and $2.5 \mathrm{ml} 1 \mathrm{~N}$ $\mathrm{HCl}$ was added. The solution was diluted to a volume of $50 \mathrm{ml}, 25 \mathrm{ml}$ EDTA was added and the solution was heated at fuming temperature for 15 minutes. The amount of EDTA was titrated by a $\mathrm{ZrOCl}_{2}$ solution using xylenol orange as indicator. Selenium was reduced to the elemental state in a stream of $\mathrm{SO}_{2}$ and weighed after drying. Thallium was oxidized by $\mathrm{KIO}_{3}$ in acid solution and the equivalent point was determined by potentiometric measurements. A platinum electrode was used as indicator electrode and 
Table 1 Results of the chemical analysis (mass\%).

\begin{tabular}{c|l|l|l|l|l|l}
\hline \multirow{2}{*}{ Compound } & \multicolumn{3}{c|}{ Calculated } & \multicolumn{4}{c}{ Observed } \\
\hline \multirow{2}{*}{$\mathrm{Tl}_{4} \mathrm{GeSe}_{4}$} & $\mathrm{Tl}$ & $\mathrm{Ge}$ & $\mathrm{Se}$ & $\mathrm{Tl}$ & $\mathrm{Ge}$ & $\mathrm{Se}$ \\
& 67.8 & 6.0 & 26.2 & $67.7(1)$ & $5.9(1)$ & $26.4(1)$ \\
\hline
\end{tabular}

Table 2 Crystallographic data for $\mathrm{Tl}_{4} \mathrm{GeSe}_{4}$ and experimental details of the structure determination.

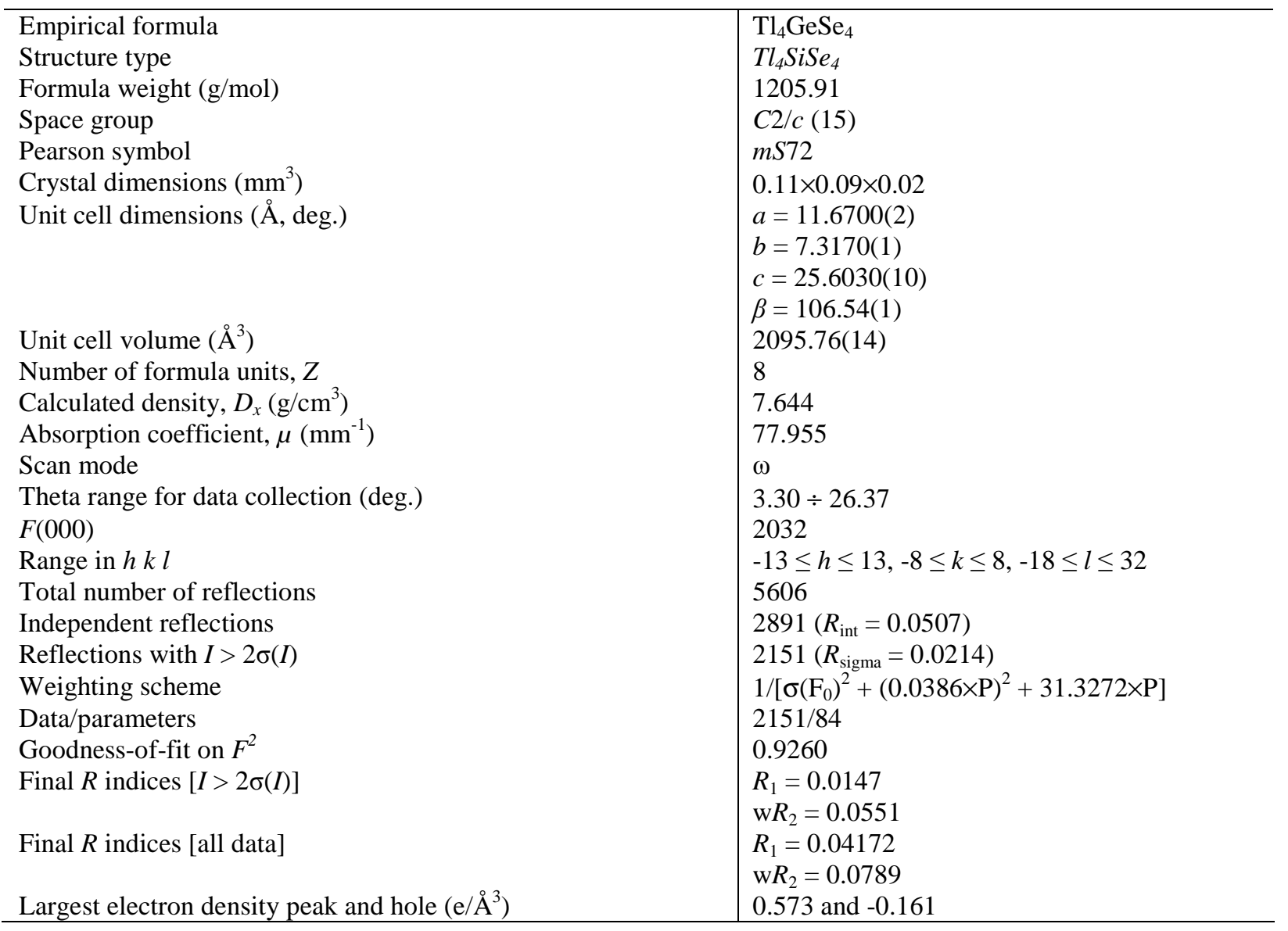

a standard calomel electrode as reference electrode. The results of the chemical analysis are given in Table 1.

\section{Results and discussion}

The analysis of the systematic absences and the statistical test of the distribution of E-values [12] suggest that the structure of $\mathrm{Tl}_{4} \mathrm{GeSe}_{4}$ is centrosymmetric. Structure solution and refinement were also performed in the non-centrosymmetric space group $C c$. The results clearly indicate that $\mathrm{Tl}_{4} \mathrm{GeSe}_{4}$ crystallizes in the centrosymmetric space group $C 2 / c$. Table 2 contains crystallographic data and details of the data collection and structure refinement. Atomic parameters and anisotropic displacement parameters are listed in Table 3. A projection of the structure of $\mathrm{Tl}_{4} \mathrm{GeSe}_{4}$ onto the $x z$ plane is shown in Fig. 1a, emphasizing the packing of $\left[\mathrm{GeSe}_{4}\right]$ tetrahedra and the shortest distances between $\mathrm{Tl}^{+}$cations. Each $\mathrm{Tl}^{+}$cation in the structure is coordinated by four separate $\left[\mathrm{GeSe}_{4}\right]^{4-}$ anions (Fig. 1b). They adopt slightly different forms of anion coordination, which may, however, all be described as strongly distorted octahedra. The $\left[\mathrm{GeSe}_{4}\right]^{4-}$ anions are surrounded by nine $\mathrm{Tl}^{+}$cations in the shape of an irregular coordination polyhedron (Fig. 1c).

A list of interatomic distances is reported in Table 4. The Tl-Tl, Tl-Se and Ge-Se distances do not show considerable deviation from the sums of radii of the components. When we compare the $\mathrm{Tl}_{4} \mathrm{GeSe}_{4}$ compound with the $\mathrm{Tl}_{4} \mathrm{SiSe}_{4}$ prototype we notice a relative shortening of the Tl-Se distances $(2.8654 \AA$ for $\mathrm{Tl}_{4} \mathrm{GeSe}_{4}$ but $3.000 \AA$ for $\mathrm{Tl}_{4} \mathrm{SiSe}_{4}$ ), which indicates strengthening of the cation-anion interaction. 
a)

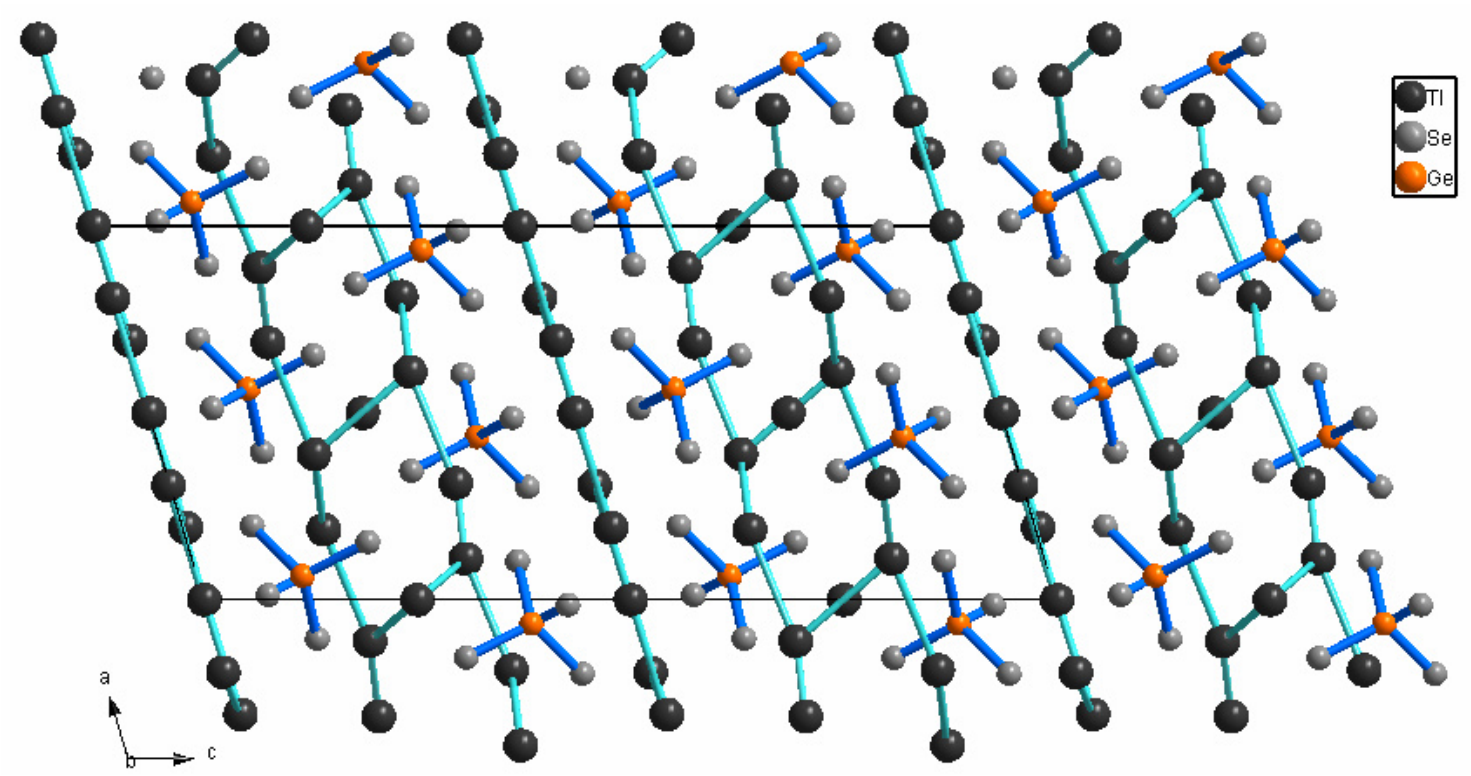

b)
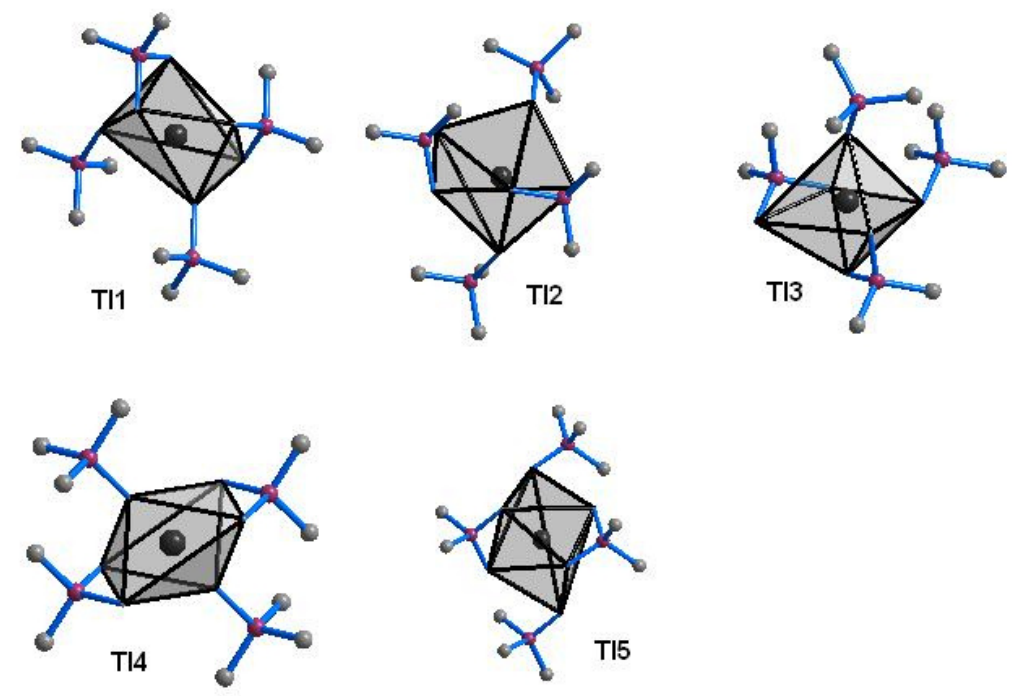

c)

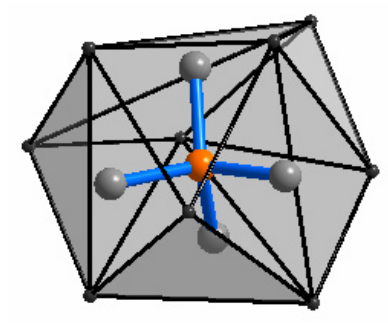

Fig. 1 Crystal structure of $\mathrm{Tl}_{4} \mathrm{GeSe}_{4}$ projected on the $x z$ plane. Packing of $\left[\mathrm{GeSe}_{4}\right]$ tetrahedra and $\mathrm{Tl}^{+}$split nets (a), surrounding of the $\mathrm{Tl}^{+}$ions by $\left[\mathrm{GeSe}_{4}\right]$ tetrahedra (b), and surrounding of the $\left[\mathrm{GeSe}_{4}\right]$ tetrahedra by $\mathrm{Tl}^{+}$cations (c). 
Table 3 Atomic coordinates and displacement parameters $\left(\AA^{2}\right)$ for $\mathrm{Tl}_{4} \mathrm{GeSe}_{4}$.

\begin{tabular}{|c|c|c|c|c|c|c|}
\hline Atom & Wyckoff & $x / a$ & $y / b$ & \multicolumn{2}{|c|}{$z / c$} & $U_{e q}$ \\
\hline Tl1 & $8 f$ & $0.19374(2)$ & $0.53903(4)$ & $0.00248(1)$ & & 637(9) \\
\hline $\mathrm{Tl} 2$ & $8 f$ & $0.38974(3)$ & $0.27749(5)$ & $0.17946(1)$ & & $91(1)$ \\
\hline $\mathrm{Tl} 3$ & $8 f$ & $0.31210(3)$ & $0.37192(4)$ & $0.33578(1)$ & & $38(1)$ \\
\hline $\mathrm{Tl} 4$ & $4 a$ & 0 & 0 & 0 & & $13(2)$ \\
\hline $\mathrm{Tl} 5$ & $4 e$ & 0 & $0.16948(5)$ & $1 / 4$ & & $96(1)$ \\
\hline $\mathrm{Se} 1$ & $8 f$ & $0.19790(5)$ & $0.21966(9)$ & $0.08228(3)$ & & $02(1)$ \\
\hline $\mathrm{Se} 2$ & $8 f$ & $0.51317(5)$ & $0.15659(7)$ & $0.07569(2)$ & & $10(1)$ \\
\hline $\mathrm{Se} 3$ & $8 f$ & $0.10385(5)$ & $0.19769(10)$ & $0.38092(3)$ & & $23(2)$ \\
\hline $\mathrm{Se} 4$ & $8 f$ & $0.15477(5)$ & $0.45964(9)$ & $0.21225(2)$ & & $79(1)$ \\
\hline $\mathrm{Ge}$ & $8 f$ & $0.06410(7)$ & $0.38029(12)$ & $0.12404(3)$ & & $26(2)$ \\
\hline Atom & $U_{11}$ & $U_{22}$ & $U_{33}$ & $U_{12}$ & $U_{13}$ & $U_{23}$ \\
\hline Tl1 & $0.03733(15)$ & $0.04239(15)$ & $0.05897(17)$ & $-0.0073(1)$ & $0.01304(11)$ & $0.00104(11)$ \\
\hline $\mathrm{Tl} 2$ & $0.04252(16)$ & $0.0594(2)$ & $0.0716(2)$ & $0.00087(13)$ & $0.01016(14)$ & $-0.00916(14)$ \\
\hline $\mathrm{Tl} 3$ & $0.05127(17)$ & $0.05009(17)$ & $0.05178(17)$ & $0.01150(12)$ & $0.00125(12)$ & $0.00351(12)$ \\
\hline $\mathrm{Tl} 14$ & $0.0460(2)$ & $0.0443(2)$ & $0.1232(5)$ & $-0.0231(2)$ & $-0.0251(3)$ & $0.0263(3)$ \\
\hline $\mathrm{Tl} 5$ & $0.0651(2)$ & $0.03818(19)$ & $0.04411(19)$ & 0 & $0.01301(17)$ & 0 \\
\hline Se1 & $0.0356(3)$ & $0.0404(3)$ & $0.0417(3)$ & $0.0128(3)$ & $0.0059(2)$ & $-0.0046(3)$ \\
\hline $\mathrm{Se} 2$ & $0.0368(3)$ & $0.0136(2)$ & $0.0458(3)$ & $0.01685(19)$ & $0.0166(2)$ & $0.00818(19)$ \\
\hline $\mathrm{Se} 3$ & $0.0219(3)$ & $0.0493(4)$ & $0.0539(4)$ & $0.0227(2)$ & $0.0075(2)$ & $-0.0009(3)$ \\
\hline $\mathrm{Se} 4$ & $0.0331(3)$ & $0.0404(3)$ & $0.0297(3)$ & $-0.0016(2)$ & $-0.0084(2)$ & $0.0006(2)$ \\
\hline $\mathrm{Ge}$ & $0.0402(4)$ & $0.0526(5)$ & $0.0592(5)$ & $0.0021(3)$ & $0.0045(3)$ & $0.0165(4)$ \\
\hline
\end{tabular}

$U_{e q}$ is defined as one third of the trace of the orthogonalized $U_{i j}$ tensor. The anisotropic displacement factor exponent takes the form $-2 \pi^{2}\left[\left(h a^{*}\right)^{2} U_{11}+\ldots+2 k l b * c^{*} U_{23}\right]$.

Table 4 Interatomic distances $(\AA)$ for $\mathrm{Tl}_{4} \mathrm{GeSe}_{4}$.

\begin{tabular}{|c|c|c|c|c|c|}
\hline Tl1 & $\begin{array}{l}\mathrm{Se} 2 \\
\mathrm{Se} 1 \\
\mathrm{Se} 2 \\
\mathrm{~T} 11 \\
\mathrm{Se} 1 \\
\mathrm{Se} 3 \\
\mathrm{Se} 3 \\
\mathrm{~T} 14 \\
\end{array}$ & $\begin{array}{l}3.0222(6) \\
3.0953(8) \\
3.3079(7) \\
3.3715(4) \\
3.3844(8) \\
3.4386(8) \\
3.5552(8) \\
3.6040(3) \\
\end{array}$ & Se1 & $\begin{array}{l}\mathrm{Ge} \\
\mathrm{Tl} 2 \\
\mathrm{Tl1} \\
\mathrm{Tl} \\
\mathrm{Tl} \\
\mathrm{Tl} \\
\mathrm{Tl}\end{array}$ & $\begin{array}{l}2.4317(12) \\
2.8654(7) \\
3.0953(8) \\
3.0959(6) \\
3.3209(8) \\
3.3844(8)\end{array}$ \\
\hline $\mathrm{T} 12$ & $\begin{array}{l}\text { Se1 } \\
\text { Se4 } \\
\text { T15 } \\
\text { Se3 } \\
\text { Se2 } \\
\text { T13 } \\
\end{array}$ & $\begin{array}{l}2.8654(7) \\
3.3631(7) \\
3.4381(5) \\
3.4518(8) \\
3.4779(7) \\
3.6756(5) \\
\end{array}$ & $\mathrm{Se} 2$ & $\begin{array}{l}\text { Ge } \\
\text { T11 } \\
\text { T13 } \\
\text { T14 } \\
\text { T11 } \\
\text { T12 } \\
\end{array}$ & $\begin{array}{l}2.3567(10) \\
3.0222(6) \\
3.0243(6) \\
3.1501(5) \\
3.3079(7) \\
3.4779(7) \\
\end{array}$ \\
\hline $\mathrm{Tl} 3$ & $\begin{array}{l}\mathrm{Se} 2 \\
\mathrm{Se} 3 \\
\mathrm{Se} 4 \\
\mathrm{Se} 1 \\
\mathrm{Se} 4 \\
\mathrm{~T} 12\end{array}$ & $\begin{array}{l}3.0243(6) \\
3.2352(8) \\
3.2372(6) \\
3.3209(8) \\
3.3215(7) \\
3.6756(5)\end{array}$ & $\mathrm{Se} 3$ & $\begin{array}{l}\text { Ge } \\
\text { T15 } \\
\text { T13 } \\
\text { T11 } \\
\text { T12 } \\
\text { T11 } \\
\end{array}$ & $\begin{array}{l}2.3454(11) \\
3.2302(8) \\
3.2352(8) \\
3.4386(8) \\
3.4518(8) \\
3.5552(8)\end{array}$ \\
\hline $\mathrm{Tl} 4$ & $\begin{array}{l}\mathrm{Se} 1 \\
\mathrm{Se} 1 \\
\mathrm{Se} 2 \\
\mathrm{Se} 2 \\
\mathrm{~T} 11 \\
\mathrm{~T} 11\end{array}$ & $\begin{array}{l}3.0959(6) \\
3.0959(6) \\
3.1501(5) \\
3.1501(5) \\
3.6040(3) \\
3.6040(3)\end{array}$ & $\mathrm{Se} 4$ & $\begin{array}{l}\mathrm{Ge} \\
\mathrm{T} 15 \\
\mathrm{~T} 13 \\
\mathrm{~T} 13 \\
\mathrm{~T} 12\end{array}$ & $\begin{array}{l}2.2796(9) \\
3.1141(7) \\
3.2372(6) \\
3.3215(7) \\
3.3631(7)\end{array}$ \\
\hline T15 & $\begin{array}{l}\mathrm{Se} 4 \\
\mathrm{Se} 4 \\
\mathrm{Se} 3 \\
\mathrm{Se} 3 \\
\mathrm{~T} 12 \\
\mathrm{Tl} 2 \\
\end{array}$ & $\begin{array}{l}3.1141(7) \\
3.1141(7) \\
3.2302(8) \\
3.2302(8) \\
3.4381(5) \\
3.4381(5)\end{array}$ & $\mathrm{Ge}$ & $\begin{array}{l}\mathrm{Se} 4 \\
\mathrm{Se} 3 \\
\mathrm{Se} 2 \\
\mathrm{Se} 1\end{array}$ & $\begin{array}{l}2.2796(9) \\
2.3454(11) \\
2.3567(10) \\
2.4317(12)\end{array}$ \\
\hline
\end{tabular}




\section{Conclusions}

The $\mathrm{Tl}_{4} \mathrm{GeSe}_{4}$ compound crystallizes in space group $C 2 / c\left(\mathrm{Tl}_{4} \mathrm{SiSe}_{4}\right.$ structure type). The structure consists of separate $\left[\mathrm{GeSe}_{4}\right]$ tetrahedra, which occupy voids between $\mathrm{Tl}^{+}$split nets. Strengthening of the cationanion interactions was observed with respect to closely related compounds.

\section{References}

[1] A.A. Gotuk, M.B. Babanly, A.A. Kuliev, Izv. Akad. Nauk SSSR, Neorg. Mater. 15(3) (1979) 530-531.

[2] V.B. Lazarev, E.Yu. Peresh, V.I. Starosta, Zh. Neorg. Khim. 28(8) (1983) 2097-2099.

[3] N.A. Kulieva, M.B. Babanly, Izv. Akad. Nauk SSSR, Neorg. Mater. 17(3) (1981) 421-423.

[4] P. Houenou, R. Eholié, C. R. Seances Acad. Sci., Ser. C 16 (1976) 731-733.
[5] N.A. Kulieva, M.B. Babanly, Zh. Neorg. Khim. 28(6) (1983) 1557-1560.

[6] G. Eulenberger, Acta Crystallogr. C 42 (1986) 528-534.

[7] G. Eulenberger, Z. Kristallogr. 145 (1977) 427436.

[8] K.O. Klepp, Z. Naturforsch. B 39 (1984) 705712.

[9] G. Akinocho, P. Houenou, S. Oyetola, R. Eholié, J.C. Jumas, J. Olivier-Fourcade, M. Maurin, J. Solid State Chem. 93 (1991) 336-340.

[10] G.M. Sheldrick, SHELXS, Program for the Solution of Crystal Structures, University of Göttingen, Germany, 1997.

[11] G.M. Sheldrick, SHELXL-97, Program for Crystal Structure Refinement, University of Göttingen, Germany, 1997.

[12] L.J. Farrugia, J. Appl. Crystallogr. 32 (1999) 837-838. 